\title{
Tracking Interpersonality in Research Article Abstract: A Diachronic Study of Dynamic Nature of Genre
}

\author{
Arezou Bakhtiari \& Ali Akbar Khomeijani Farahani \\ arezou.bakhtiari@ut.ac.ir,farahani@ut.ac.ir \\ Faculty of Foreign Languages and Literatures, University of Tehran, Tehran, IRAN
}

\begin{abstract}
This study reports on interpersonality in a diachronic-contrastive investigation in Research Article (RA) abstracts. The study analyzed a corpus of 180 RA abstracts from two journals of Psychological Bulletin and Personality and Individual Differences over the last three decades. This paper uses Hyland's (2005b) Stance Model of Interaction and Hyland \& Tse's (2005) Classification of Sentences Containing Evaluative that in order to explore interpersonality. The results of this study revealed that authors of these journals adopted different stance and positioning over time in their writing. In addition, the findings of this paper did not corroborate previous research findings that $R A$ abstracts exhibit high number of boosters. In relation to writing pedagogy, the results of this study can help the scholars to frame their papers in order to publish them in English-medium journals.
\end{abstract}

Keywords: Genre, diachronic study, stance, evaluation

\section{Introduction}

With regard to dynamic nature of genres, Hyland and Jiang (2016) mentioned a dearth of knowledge about the historical process of metadiscourse whereas the quality of Research Article (hereafter RA) is germane to authors' ability to leave a credible impression in the mind of readers to gain their endorsement. They, subsequently, viewed Gillaerts and Van de Velde (2010) as the only diachronic study of metadiscourse and noted that how tracking professional writing changes is important to hinge language to its context; there is a need to analyze the changes of language rather than merely focusing on itself (Hyland \& Jiang, 2018). About the importance of metadiscourse changes, Hyland (2005a) stated that "These changes and tendencies are still unclear, however, and careful analysis of patterns of change would be enormously beneficial to diachronic studies of academic and professional communities and to critical discourse analysis" (2005a, p. 202). Hu and Cao (2011), too, addressed little attention to the comparative studies of metadiscourse devices particularly in RA abstracts. Nonetheless, they only investigated hedges and boosters in empirical versus non-empirical RAs and not particularly in RA abstracts.

Evaluation, stance, and metadiscourse are linguistic devices by which writers acknowledge the readers' presence in academic propositional material (Hyland \& Tse, 2005). They considered that-clauses as a potent structure enabling writers to thematize their evaluative ideas in their interpersonal act of writing and mentioned the dearth of studies on this feature. Gillaerts and Van de Velde (2010) implied that the study of interpersonality in the academic context can be augmented with the study of other aspects of stance such as evaluation. They assumed that the 
study of stance and evaluation together can cover the blind spots in academic prose. Moreover, it seems that there has been no paper which analyzed a contrastive study between two journals with high and low impact factors in Psychology discipline. Hence, this study aimed to conduct a diachronic-contrastive analysis of stance markers and evaluative that-clauses in RA abstracts of the papers of Psychology discipline in two journals of Psychological Bulletin and Personality and Individual Differences over the last 30 years. The ultimate goal of this study is to help novice writers to frame their papers to get them published in English-medium journals and become internationally visible.

Gaining the ground among New Rhetorical researchers, Miller (1984) introduced her revolutionary paper by stabilizing the rhetorical concept of genre and its primacy as social action and stated that genre is a rule-governed mixture of form and substance within particular situation. In this action-based fusion, substance with its semantic value merges with form with its both semantic and syntactic values to be served as substance or genre at higher levels of meaning-as-action hierarchy. This fusion centers on rhetorical situation, and to understand situation, it is necessary to weed out materialistic views. For our action to be interpretable in situation, a requisite of awareness of socially recognizable ways to get our social motives across is a must. Hence, "genre refers to conventional category of discourse based in large-scale typification of rhetorical action; as action, it requires meaning from situation and from the social context in which that situation arose" (Miller, 1984, p. 163). This concept of genre is also adopted by Bazerman, as shown in his statement: "My Analysis of genre follows Miller" (1988, p. 7). As a writing teacher, he found that texts can be investigated only with the sociopsychological gist of that text. Writing is a multidimensional activity because in one particular rhetorical moment and in one particular situation, one particular insight of these two sparks the writer to use language. Genres are typified actions in typified situations with ephemeral stable language.
"A genre comprises a class of communicative events, the members of which share some set of communicative purposes. These purposes are recognized by expert members of the parent discourse community, and thereby constitute the rational for the genre. This rational shape the schematic structure of the discourse and influences and constrains choice of content and style" (Swales, 1990, p. 58).

A working definition of genre was provided by Swales (1990) who is one of the luminaries in genre analysis. In his attempt at setting forth the theoretical framework of genre applicable in language learning, he noted that shared communicative purpose is the common ground for communicative events in gathering around genres. The name of communicative event suggests that language must be essential part of that event. Thus, non-verbal activities or those in which language is incidental such as dancing, driving, and playing are not regarded as communicative instances. Communicative purpose as the privileged property of genre in English for Specific Purposes (ESP) grounds for the appeal to the conventions of generic content, style, and structure. ESP camp is most wellknown for Swales' move-step analysis in academic and research settings, though by 1998 he emphasized the integration of text, context, and author's voice in generic approach.

Style, one of the key features in Swales' wording, is assumed as identity by Fairclough (2003). As a discoursal aspect, it attests to who you are through how you use language; that is the matter of identification. Hyland (2003, 2005a), although acknowledged the pedagogical values of cognitive generic approach, demonstrated that what is lacking is the social concept of language use. In the socio-cognitive process of writing, writers will know not only how to project their own being, but also how to address readers rhetorically to go beyond the text and forge effective relationship in discourse communities (Hyland, 2003, 2005a). In the process of overhauling the concept of invention as prewriting activity, Bawarshi (2003) superseded the locus of invention from writer-based 
cognitive activities with pre-social mode of socializing activities. She argued that traditional invention, although was successful in shifting the attention from text to writers, is still unsuccessful with regard to social dimension of writing. This can be brought into misapprehension that these social kinds of prewriting activities favor people with their privileged culture and society in genre, but it turns to be on the opposite side. It is a starting point to figure out the social, rhetorical, and linguistic conventions of genre and get them to work in particular situation; it breaks down the invisible yet daunting sociocultural borders. Paltridge (1995) called for describing genre from both social and cognitive aspects. With his pragmatic orientation in exploring instances of genre, he concluded his article by a quotation from Biber: "Genres are defined and distinguished on the basis of systematic nonlinguistic criteria, and they are valid in those terms" (1989, p. 39).

"A compact genre" is the notion taken up by Jiang and Hyland (2017) to refer to RA abstracts by which readers either find the paper worthwhile to keep their eyes on the page or they abandon their faith to the words and the whole paper is doomed to be left unread $(2017$, p. 3). Factoring four uses in for RA abstracts, Huckin (2001) associated RA abstracts with terms of "mini texts" giving the reader a pithy summery of the paper, "screening devices" helping the readers with the decision of whether to keep reading the rest of the article, "previews" providing the readers with a frame of what lies in the paper, and "aids to indexing" (2001, p. 93).

Introduced by Harris (1959) as a guide to monitor possible responses of the intended recipients of the written/spoken discourse, metadiscourse has been attracting the research focus in academic register (Crosthwaite, Cheung \& Jiang, 2017; Hyland, 2017; Hyland \& Jiang, 2018; Qin \& Uccelli, 2019). Metadiscourse, attesting to the interpersonal nature of discourse, offers a persuasive way for writers to project themselves through their rhetorical choices to achieve their communicative ends. This notion was conceptualized into various linguistic constructs such as posture (Grabe,
1984), evidentiality (Chafe \& Nicholas, 1986), positioning (Harré \& Van Langenhove, 1999), stance (Biber \& Finegan, 1989), evaluation (Hunston \& Thompson, 2000), appraisal (Martin $\&$ White, 2005), and metadiscourse (Hyland, 2005a).

The Language of Evaluation, the title of one 2005 cogently-argued book, grew out of the Systemic Functional Linguistics (SFL) rhetoricians' looking at genre as staged, goaloriented social process to unfold language as discourse. Martin and White (2005), concerned with rhetorical articulation than logical veneer of language, situated their systemic functional mapping of stance named appraisal at the third level of language realization that is discourse semantics. Hence, appraisal system connotes how writers/speakers invest in linguistic mechanism to convey the depth of feelings, monopolize specific authority, and get on with prospective readers/listeners. Their idea was to construe appraisal as impetus for grasping tenor; a register variable concerned with the role, nature, and status of communication participants. As an interpersonal system in SFL, appraisal is treated as a tripartite semantic resource with its attitude, engagement and graduation domains. Attitudinal resources are manipulated by affection, judgment, and appreciation. Engagement casts further light on dialogic nature of written communication; they are resources with disclaim markers to voice contradiction, proclaim markers to sprinkle certainty, entertain markers to keep propositions open for subjectivity, and attribute markers to play external voices. Meanings are not flat; graduation devices are used to modulate the intensity of propositional meanings. Force and focus are two sub-categories for this modification; Force with its scaling nature to turn the volume of intensity up/down and focus with its complementary help for categories which are not scalable. It operates on the basis of prototypicality to give its verdict on membershipness. Under focus, graduation can have either softening values to marginalize the membership of an instance or sharpening values to see an instance a clear member of one 
category. In this sense, focus operates like hedges and boosters.

"Evaluation is the broad cover term for the expression of the speaker's or writer's attitude or stance towards, viewpoint on, or feelings about the entities or propositions that he or she is talking about" (Hunston \& Thompson, 2000, p. 5). Hunston \& Thompson (2000) considered evaluation with its three functions of expressing writers' perspectives and values, forging a communicative relation between writers (or speakers) and readers (or hearers), and organizing the discourse and its importance. They, too, outlined four parameters of good-bad, level of certainty, expectedness, and importance for evaluation.

Gillaerts and Van de Velde (2010), in their analysis of 72 RA abstracts, aimed at diachronic study of metadiscourse. They argued for considering RA abstract as a separate genre in which a wealth of boosters assists the writers with fortifying their claims. They, too, found a steady decline in the frequency of boosters and attitude markers over time in RA abstracts. They stated that this drop can be in part because of either the movement of linguistics towards hard science or scholars' deliberate shying away from making strong claims.

In a doubly contrastive study of textual function of metadiscourse, Dahl (2004) worked on 180 papers collected from three disciplines of economics, linguistics and medicine in three languages of English, French and Norwegian with the aim to see whether language or discipline has more dominant effect on the pattern of metatext in academic prose. In so doing, she restricted metadiscourse to meta-elements with their textual realizations whose function is to manifest the writers' awareness of the readers in their interpersonal discourse. In her classification, meta-elements consist of two categories of locational metatext referring to the text and rhetorical metatext including meta-elements that guide the readers in the argumentative process of the articles. The second category comprises verbs that realize rhetorical acts. She concluded that in economics and linguistics, language is more influential in the pattern of metatext and this can be partly due to less formalized and more subjective nature of these fields. Medicine for all languages showed a few instances of metatext and this can be attributed to stable and less subjectively-interpreted nature of the papers in this discipline (Dahl, 2004).

In his work on language as social phenomenon, Hyland (2005a) acknowledged socio-cognitive view of interaction between writers and readers; rhetorically, writing is the art of making intelligent choices. Writers, equipped with the knowledge of metadiscourse, can leave a favorable representation of themselves in the mind of readers. Seeing this way, he dismantled metadisccourse in two categories of interactive and interactional resources concerned with text organization and the perception of authorial persona respectively. Interactive resources consist of five components of transition, frame markers, endophoric markers, evidentials, and code glosses. They help reader through the text by denoting semantic relation between main clauses, sequencing discourse acts, transferring the attention of the reader to other parts of the text, referring to the external resources of text information, and restating the meaning of ideational materials.

With interactional category, on the other hand, the writers involve the readers in their discursive arguments. Writers' reluctance to make claims in order to avoid commitment in propositional meaning is manifested through hedges; they help writers to have cautious reasoning. Hence, the readers can bring their own interpretation into the topic. Boosters, in contrast to hedges but complementary to them, boost the writers' confidence about their statements. Attitude markers express writers' affective values to their wordings. Deployment of first person pronouns and possessives to explicitly address the writer is under the auspices of self-mention markers. Explicitly addressing the reader is at the realm of the engagement markers. Hyland (2005b) subsequently considered stance and engagement markers as two sub-categories of interaction and commented that text quality is augmented by 
writers' cognizance of how words convene to put forth rhetorical consequences. Indeed, it suggests the importance of socio-cultural context in particular genre and social community in adopting specific rhetorical resources in writing.

\section{Methodology}

In order to track down the historical process of metadiscourse resources, we selected a total of $180 \mathrm{RA}$ abstracts to trace their dynamic nature over the past 30 years from 1985 to 2015. We singled out Psychology discipline for this purpose as a member of soft disciplines. The reason for this selection was that it seems this field has not been considered in any study for its RA abstracts and their diachronic dynamics. The Psychological Bulletin and Personality and Individual Differences were the journals from each of which, 90 RA abstracts were taken. The reasons for choosing these journals were their far and away impact factors based on the Thomson Reuters' Web of Knowledge ISI in 2017 and their history of publishing across different periods of time in order to have the necessary corpora for this study. Table 1 represents the characteristics of these two journals.

Table 1.

The Information About Two Journals Based on Thomson Reuters' Web of Knowledge ISI in 2017

\begin{tabular}{lll}
\hline Psychological Bulletin & & Personality and Individual Differences \\
\hline Impact factor: 13.25 & & Impact factor: 1.96 \\
Published from: 1904 -present & & Published from: 1980 -present \\
Publisher: American Psychological Association & & Publisher: Elsevier \\
\hline
\end{tabular}

Hyland (2005b), concerned with communicative nature of language in its particular context, presented a model of stance consisting of writers' epistemic perspective, affective point of view, and their explicit presence in the text. Stance "represents a coherent concept and body of research that is worth discussing in its own right" (Hyland \& Jiang, 2016, p. 6). Table 2 shows the stance model of interaction developed by Hyland (2005b).

Table 2.

Stance Features of Interaction (Hyland, 2005b)

\begin{tabular}{|c|c|c|}
\hline Stance Features & Function & Examples \\
\hline \multirow{6}{*}{$\begin{array}{l}\text { Hedges } \\
\text { Boosters } \\
\text { Attitude markers } \\
\text { Self-mention }\end{array}$} & Withhold commitment and open & Might; perhaps; possible; about \\
\hline & dialogue & In fact; definitely; it is clear that \\
\hline & Emphasize certainty or close dialogue & Unfortunately; I agree; \\
\hline & Express writer's attitude to & surprisingly \\
\hline & proposition & I; we; me; our \\
\hline & Explicit reference to author(s) & \\
\hline
\end{tabular}

Hyland and Tse (2005), concerned with evaluative dimension of academic discourse, presented a model of classification of sentences containing evaluative that which is a "construction for expressing evaluative meaning in academic discourse as it allows the writer to 
thematize the evaluation, making the attitudinal meaning the starting point of the message and the perspective from which the content of the that-clause is interpreted" (2005, p. 124). This model consists of four aspects of evaluative entity, evaluative stance, evaluative source, and expression. Evaluative entity comprises four categories of the author's own findings, evaluation of the findings of the previous studies, expression of the author's goals, and evaluation of research methods, models, or theories. With evaluative stance, writers express their attitudinal or epistemic stance towards the rhetorical propositions. In evaluative source, writers can attribute the source of their evaluation to human, abstract, or concealed resources. The last aspect of this model is either non-verbal or verbal expression of evaluation. Table 3 represents this model.

Table 3.

Classification of Sentences Containing Evaluative That (Hyland and Tse, 2005)

\begin{tabular}{|c|c|c|}
\hline Aspect & Subcategories & Examples \\
\hline \multirow[t]{4}{*}{ Evaluative entity } & $\begin{array}{l}\text { (a) Evaluation of the author's own } \\
\text { findings }\end{array}$ & $\begin{array}{l}\text { Our findings show that the museum } \\
\text { visit can be seen as } 6 \text { distinct stages }\end{array}$ \\
\hline & $\begin{array}{l}\text { (b) Evaluation of the findings of the } \\
\text { previous studies }\end{array}$ & $\begin{array}{l}\text { Although research shows that vocab } \\
\text { can be acquired directly through } \\
\text { reading... }\end{array}$ \\
\hline & (c) Expression of the author's goals & $\begin{array}{l}\text { We seek to show that similar mean can } \\
\text { be used in other retail situations. }\end{array}$ \\
\hline & $\begin{array}{l}\text { (d) Evaluation of the research methods, } \\
\text { models, theories }\end{array}$ & $\begin{array}{l}\text { The problem with this method is that it } \\
\text { is not easily transferable to... }\end{array}$ \\
\hline \multirow[t]{3}{*}{ Evaluative Stance } & (a) Attitudinal: (i) affect & I hope that, It is important to note that \\
\hline & (ii) obligation & It must be recognized that \\
\hline & (b) Epistemic & It is likely that, we prove that \\
\hline \multirow[t]{3}{*}{$\begin{array}{l}\text { Evaluative } \\
\text { source }\end{array}$} & $\begin{array}{l}\text { (a) Human- either the author or other } \\
\text { humans }\end{array}$ & We show that, Smith notes that \\
\hline & (b) Abstract entity- inanimate source & The findings indicate that \\
\hline & $\begin{array}{l}\text { (c) Concealed- writer does not identify } \\
\text { the source }\end{array}$ & $\begin{array}{l}\text { It is well-known that, a general finding } \\
\text { is that }\end{array}$ \\
\hline \multirow[t]{6}{*}{ Expression } & (a) Non-verbal__Noun predicate & The conclusion advanced is that \\
\hline & Adjectival predicate & It is possible that, it is known that \\
\hline & (b) Verbal predicate & \\
\hline & $\begin{array}{l}\text { (i) Research acts-actions in the real } \\
\text { world }\end{array}$ & $\begin{array}{l}\text { This demonstrates that, The analysis } \\
\text { indicates that, They found that }\end{array}$ \\
\hline & (ii) Discourse acts-linguistic activities & We argue that, I propose that \\
\hline & (iii) Cognitive acts-mental processes & They perceive that, we believe that \\
\hline
\end{tabular}


This study deployed these two models to investigate the diachronic process of writers' position towards the discourse under discussion. After collecting all the $180 \mathrm{RA}$ abstracts, the frequency of stance markers and that-clauses were revealed through the AntConc program. This stage of frequency counts included both American and British spelling of the words. For stance markers, $20 \%$ of the corpora were assessed through the repeated reading of each sample by two raters (authors of this study) independently to assure the metadiscoursal function of these linguistic devices and interrater agreement between the raters was 95\%. For that-clauses, all the corpora were handed over to the raters to omit the instances of thatclauses with other grammatical functions through the repeated reading of each sample independently. This time, the inter-rater agreement between the raters was $96 \%$. The raw frequencies, then, were normalized to 1000 words for ease of comparison. Statistical significance was also recognized by Chi-Square test in order to find out whether there is any significant difference between the authors of the journals in their use of the combination of stance markers and evaluative that-clauses in their papers over time.

\section{Findings and Discussion}

How the writers' rhetorical choices of interpersonal communication changed over time in two journals of Psychological Bulletin and Personality and Individual Differences was a question posed by this paper. This study, following Hyland's (2005b) stance model and Hyland and Tse's (2005) classification of sentences containing evaluative that, argued to keep abreast of discursive dynamic nature of RA abstract genre that lies in how communicative purpose is manifested in effective academic writing among members of this communicative event; how writers seek a way of socializing in these two journals was the kernel of this diachronic study of RA abstracts.

\section{The Combination of Stance Markers}

Surprisingly, Figure 1 shows a telling difference in the trends of authors' overall rhetorical use of stance in two journals of Psychological Bulletin and Personality and Individual Differences. Although there was a steady increase in the deployment of stance elements among authors of Psychological Bulletin journal, there was a gradual decline in the use of these elements among writers of Personality and Individual Differences journal. Stance devices received popularity among writers of Psychological Bulletin journal over time by $31 \%$ whereas this popularity has diminished by $29 \%$ over time with the authors of Personality and Individual Differences journal. What came to our surprise more, was the starting and ending points of these two trends; they are virtually in reverse direction. Chi-Square test was applied between two variables that one has two levels (two types of journals) and the other has three levels (three years of 1985, 2000, and 2015) and there was a significant difference (log likelihood $=268.63, p<0.001$ ) between the writers of these two journals in their use of the combination of stance markers over time. 


\section{The Distribution of the Combination of Stance Markers in Two Journals over Time (per 1000 words)}

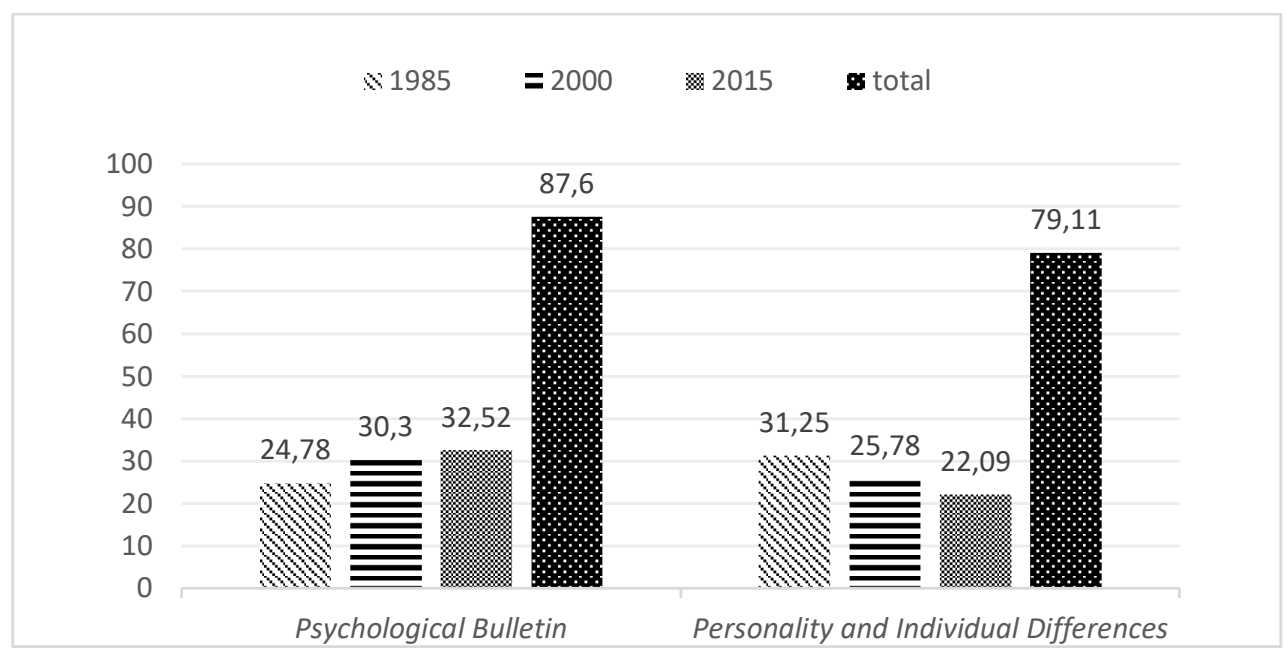

Now there is nothing better than stepping into the meticulous look at the results of this diachronic study to understand the guiding assumptions of the writers' mindsets. Figures 2 and 3 reveal the distribution of each stance markers over the last three decades in Psychological Bulletin and Personality and Individual Differences journals respectively.

\section{Chart 2.}

The Distribution of Stance Markers in Psychological Bulletin Journal over Time (per 1000 words)

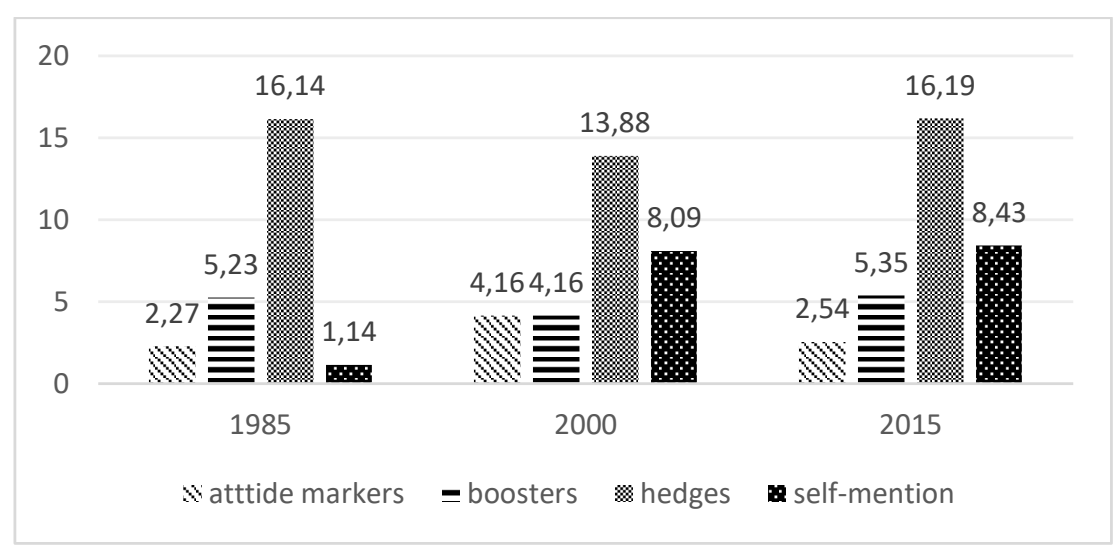




\section{Chart 3. \\ The Distribution of Stance Markers in Personality and Individual Differences Journal over Time (per 1000 words)}

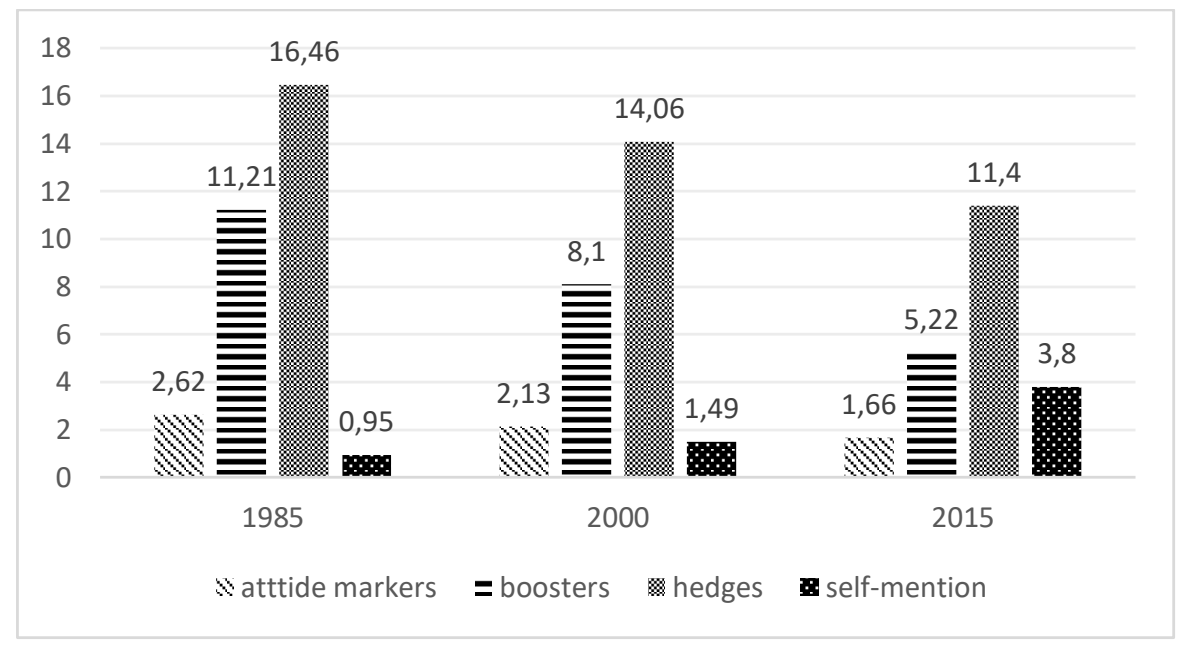

\section{Attitude Markers}

These markers are manifested through writers' personal affective view towards the propositions (see examples 1 and 2). What the result of this study indicated is that there was an overall decline of $37 \%$ in the use of affective resources among authors of Personality and Individual Differences journal. This is in evidence with what Hyland and Jiang (2016) implied; there is a drop in the employment of attitude markers in the soft science articles alongside the dynamic patterns of stance. On the other side, however, the result was different for the writers of Psychological Bulletin journal. Authors of this journal demonstrated a propensity to commingle their abstracts with affective resources more in 2000 by comparison with 1985 and 2015. The use of attitude markers is shown in the examples of 1 and 2 taken from the corpus.

(1) A strikingly similar pattern emerged for older adults, who had even stronger deficits in discriminability than children, relative to adults. (Psychological Bulletin)

(2) Interestingly, attachment style was unrelated to avoidance-oriented motivational styles. (Personality and Individual Differences)

\section{Boosters}

Writers' certainty about their arguments is boosted through the use of boosters (see examples 3 and 4). Before embarking on the contrastive analysis of the two journals, it should be noted that boosters were not the most frequent linguistic element in RA abstracts investigated by this study. This runs counter to what Gillaerts and Van de Velde (2010) stated; they implied that RA abstracts nature mandates the writers to strengthen their claims with a myriad booster. Examples 3 and 4 show the presentation of boosters in RA abstracts written by the authors of the two journals.

(3) Results revealed that observed gender differences were not explained by measurement bias and thus can be interpreted as true sex differences. (Psychological Bulletin)

(4) The results demonstrate, within an analog experiment, the relative importance of individual differences in the endorsement of non-normative beliefs. (Personality and Individual Differences) 
The findings showed a gradual drop of 53\% in the use of these certainty building markers in the RA abstracts of Personality and Individual Differences journal. For RA abstracts written by the authors of Psychological Bulletin journal, the results represented a decline in 2000 and the writers' degree of certainty about their arguments was nearly the same in 1985 and 2015. What to more is that the overall use of boosters was by far more among writers of Personality and Individual Differences journal and this is indicative of these writers' penchant for blocking out tentative reasoning; however, this confidence in their arguments has been undermined over time.

\section{Hedges}

When writers want to relish the chance of readers' opinion involvement in their writings, hedges come into sight (see examples 5 and 6). The findings of diachronic analysis of hedges in RA abstracts were akin to what they indicated about boosters; evidentiality in RA abstracts stepped into a similar path with both journals. The only difference we found was germane to overall use of hedges; authors of Psychological Bulletin journal shunned commitment to their statements more in comparison to the writers of the other journal. Examples 5 and 6, taken from the corpus, show the use of hedges.

(5) This theory, which we call the multimodal theory of affect diffusion, identifies 3 parallel multimodal mechanisms that may act as routes for affect diffusion. (Psychological Bulletin)

(6) The results indicate that a verbal processing style is associated with more effort, possibly due to the adaptation of a task-specific strategy. (Personality and Individual Differences)

Hedges were by far the most frequent stance markers in the papers of both journals and here there seems to be a tension between the result of this study and what Gillaerts and Van de Velde (2010) implied; they stated that due to the promoting nature of RA abstracts, the use of boosters is abundant versus that of hedges. With this regard, it seems that abstracts written by the authors of these two journals failed to live up their promises to hook the readers with copious number of boosters.

\section{Self-mention}

Writers' conscious intrusion into the text was the only stance element for which the findings of both journals represented a similar trend; authors of both journals chose to express themselves tremendously more over time in RA abstracts. This great increase with the use of selfmention markers demonstrates the writers' desire to leave a potent authorial stance in their abstracts. Opting for we and the authors, the writers of both journals made sparse use of $I$ (see examples 7 and 8). Coauthorship in soft science can be on account of writers' preference to have a more objective style of writing, to enjoy the benefits of sharing the resources boosting the paper's quality, and to accelerate the process of writing (Hyland \& Jiang, 2016). The use of selfmention is shown in the examples of 7 and 8 extracted from the corpus.

(7) The authors conclude by anticipating some promising future directions in this research domain. (Psychological Bulletin)

(8) We investigated the origins of individual differences in hope in adolescents based on a social-cognitive model. (Personality and Individual Differences)

\section{Evaluative "that"}

Figure 4 illustrates that there was a gentle increase in the evaluative that-clauses used by writers of Personality and Individual Differences Journal. Writers of Psychological Bulletin Journal, nonetheless, showed a different trend in employing evaluation in their RA abstract, which accords with the pattern of attitude markers over the last 30 years. The use of evaluative thatclauses in 2000 was more than 1985 and 2015 in which authors of this journal used that-clauses somewhat with the same frequency. Assuming the evaluative nature of RA abstracts, Stotesbury (2003) related this feature of RA abstracts to 
their assignment of summarizing RAs. Hence, the large number of evaluative that-clauses in RA abstracts of both journals resides in the evaluative aspect of abstracts. That is in complete accord with Hyland and Tse's (2005) conclusion that evaluative that-clauses are prevalent in academic papers; this structure helps the writers with getting the primary propositions across, being oriented around the purposes, and clarifying their position towards the statements. Moreover, writers in soft science "are less able to rely on general understandings and on the acceptance of proven quantitative methods to establish their claims and this increases the need for more explicit evaluation and engagement" (Hyland, 2005b, p. 188). From statistical point of view, there was a significant difference (log likelihood $=29.257, p<0.001$ ) between the writers of these journals in their use of evaluative that-clauses over time. Chi-Square test was applied between two variables that one has two levels (two types of journals) and the other has three levels (three years of 1985, 2000, and 2015).

\section{Figure 4. The Distribution of Evaluative That-Clauses in Abstracts of Two Journals over Time (per 1000 words)}

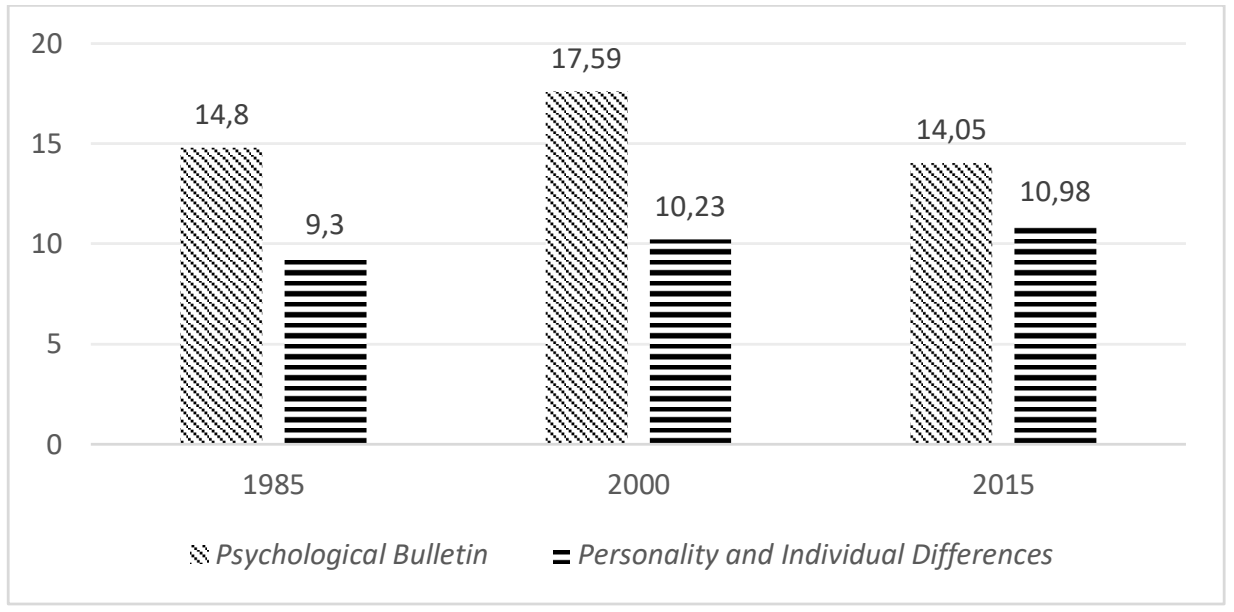

Diachronic perspective on genre gives valuable insight into how dynamic nature of genre evolves out of its rhetorical context and how these changes are manifested within discourses over time (Tardy \& Swales, 2014). The impetus for this study was to track the changes of RA abstract genre in two journals of Psychological Bulletin and Personality and Individual Differences in terms of interpersonality with regard to its stance markers and evaluative that-clauses over the last three decades. The first surprising finding of this paper was the reverse trend of these journals in drawing upon the combination of stance markers; although the writers of Psychological Bulletin journal tended to make use of these linguistic devices more over time, the authors of the other journal cut back on the employment of the combination of stance markers. The second surprising result of this paper was that except for self-mention markers, the pattern of stance markers and evaluative that-clauses were nearly the same in the abstracts written by the authors of Psychological Bulletin journal in 1985 and 2015; in the middle of this continuum, in 2000, there was either a surge for the use of attitude markers and that-clauses or a fall for the use of hedges and boosters. Writers of articles published by Personality and Individual Differences journal, unlike their peers in Psychological Bulletin journal, represented a uniform pattern of either upward for the use of self-mention markers and that-clauses or downward for the use of hedges, boosters and attitude markers over time.

The findings of this study provide evidence that RA abstract is a dynamic genre (Swales, 
2004) that shapes continuously in order to respond to changing communicative needs and evolves out of the authors' aims in particular discipline. The differences in the pattern of stance markers and evaluative that-clauses may be justified by pressure on authors to publish and increasing number of RAs published by the journals. Further studies are needed to investigate the causes of these telling differences during time. This study was not a longitudinal study and the writers of these papers were possibly different regarding their prior academic training. Moreover, some more studies can analyze why authors adopt different stances when they are writing for different journals. However, the results provided by this study can be used by scholars to notice some guidelines in the discipline of Psychology and use their rhetorical resources to publish their works and increase their chance of international visibility.

Abstracts investigated in this study did not express robust certainty about the propositional material with using boosters. Authors of these abstracts, nonetheless, represented a great tendency to emphasize subjectivity in their papers with using hedges. The wealth of hedges in RA abstracts of both journals in all the three decades goes counter to what Gillaerts and Van de Velde (2010) posited. These findings, however, are in line with what Hyland (2005b) suggested; authors in soft knowledge fields make use of hedges to underline authors' less confidence about the material under discussion. The possibility of the alignment of the reader's expectation and the writer's ideas will enhance if the writer conforms to the regularities with judicious wording of interpersonal metadiscourse. With this regard, some other studies are needed to analyze two elements of hedges and boosters thoroughly in different disciplines to see how authors project their interaction with assumed readers in RA abstracts. On the other aspect of interpersonality, writers of both journals made abundant use of evaluative that-clauses in creating propositional information in their abstracts. This is a strong structure through which writers can alert the expected readers to their contribution in their papers.
In transition from theory to practice in generic approach of writing, Johns (2011) made a distinction between "genre acquisition" and "genre awareness"; that is acquiring genre's common features and types and perceiving flexible and unstable nature of genre in relation between text, its rhetorical purpose, and its context respectively (2011, p. 57). Regarding the importance of generic instruction of interpersonality in academic texts, Crosthwaite and Jiang (2017) mentioned a need to equip the students with armory of "dialogical positioning" and acknowledged the benefits of explicit instruction of stance in writing (2017, p. 104). Hyland (2003) stated that genres, as a way of socializing through using language, cannot be wrapped up with cognitive abilities within individuals. As a socio-cognitive concept, it teaches learners not only how to forge a communicative connection in the society, but also how to be confident to change the conventions of that society. Genre analysis is assigned to explore and describe form, content, and style of the texts based on their similarities in one discourse community and by then, develops students' knowledge explicitly and raises their awareness in their practice of communication. This might summon the genre analysis to be charged with prescriptivism. It does not prescribe, however. It empowers students to be vigilant about their choices in language (Hyland, 2003, 2005a). Put succinctly, anything savoring anomalous interpretation of a linguistic string is the arch-enemy of communication and what keeps the communicative intention on a leash is the business of generic approach. This matter, particularly in written text, looms large in the absence of effective interplay between writers and readers.

This study was conducted with a limited number of RA abstracts and obviously some other studies may be needed to corroborate the findings of our work. Particularly we can suggest that ethnographic approach in investigating the RA abstracts can be of great use in analyzing the writers' view about their texts. That is what Paltridge and his colleagues carry forward 
through writing courses at University of Sydney to see how writers pin up their text to its social context (see also Bawarshi, 2003; Flowerdew \& Wan, 2010; Johns, 1997; Lillis, 2008; Paltridge, 2013). Ethnographic researches can reveal what factors may contribute to the differences discovered by this study.

\section{Conclusion}

One of the most important finding drawn by this study was the robust presence of hedges over the three decades within the RA abstracts written by authors of both journals; no matter how leading the journal of those papers is. This matter can be justified by the prevalence of evaluative that-clauses for more positioned status of the authors. Another important finding of this paper was the reverse trend of the employment of the combination of stance markers by the authors in these journals. By tracing how the rhetorical preferences of interpersonality have changed over time, we can notice how the authors' manipulation of their social stance has changed with regard to their audience. And finally in terms of pedagogical implication of our work, we genuinely hope that this paper can be of help for academic writers to notice the rhetorical consequences of the words they use to give shape to their social persona in relation to their expected readers by comparing the results of stance markers and evaluative thatclauses in these journals; clear writing grows out of clear thinking and writers' mindset can be in line with their favorable social status with their insight into stance markers and evaluative thatclauses.

\section{References}

Bawarshi, A. (2003). Genre and the invention of the writer: Reconsidering the place of invention in composition. Logan: Utah State University Press.
Bazerman, C. (1988). Shaping written knowledge: The genre and activity of the experimental article in science. Madison: University of Wisconsin Press.

Biber, D. (1989). A typology of English texts. Linguistics, 27, 3-43.

Biber, D., \& Finegan, E. (1989). Styles of stance in English: Lexical and grammatical marking of evidentiality and affect. Text, 9, 93-124.

Chafe, W. L., \& Nichols, J. (Eds.). (1986). Evidentiality: The linguistic coding of epistemology. Norwood, NJ: Ablex.

Crosthwaite, P., Cheung, L., \& Jiang, F. K. (2017). Writing with attitude: Stance expression in learner and professional dentistry research reports. English for Specific Purposes, 46, 107-123.

Crosthwaite, P., \& Jiang, K. (2017). Does EAP affect written L2 academic stance? A longitudinal learner corpus study. System, 69, 92-107.

Dahl, T. (2004). Textual metadiscourse in research articles: a marker of national culture or of academic discipline?. Journal of Pragmatics, 36 (10), 1807-1825.

Fairclough, N. (2003). Analysing discourse: Textual analysis for social research. Psychology Press.

Flowerdew, J., \& Wan, A. (2010). The Linguistic and the contextual in applied genre analysis: The case of the company audit report. English for Specific Purposes, 29, 78-93.

Gillaerts, P., \& Van de Velde, F. (2010). Interactional metadiscourse in research article abstracts. Journal of English for Academic purposes, 9(2), 128-139.

Grabe, W. (1984). Towards defining expository prose within a theory of text construction (Unpublished doctoral dissertation). University of Southern California, Los Angeles.

Harré, R., \& Van Langenhove, L. (Eds.). (1999). Positioning theory: Moral contexts of intentional action. Oxford, UK: Blackwell. 
Harris, Z. S. (1959). The transformational model of language structure. Anthropological Linguistics, 1, 27-29.

Hu, G., \& Cao, F. (2011). Hedging and boosting in abstracts of applied linguistics articles: A comparative study of English- and Chinesemedium journals. Journal of Pragmatics, 43(11), 2795-2809.

Huckin, T. (2001). Abstracting from abstracts. In M. Hewings (Ed.), Academic writing in context: Implications and applications. (pp. 93-103). London: Continuum.

Hunston, S., \& Thompson, G. (Eds.). (2000). Evaluation in text: Authorial stance and the construction of discourse. New York, NY: Oxford University Press.

Hyland, K. (2003). Genre-based pedagogies: A social response to process. Journal of Second Language Writing, 12(1), 17-29.

Hyland, K. (2005a). Metadiscourse: Exploring interaction in writing. London: Continuum.

Hyland, K. (2005b). Stance and engagement: a model of interaction in academic discourse. Discourse Studies, 7(2), 173-192.

Hyland, K. (2017). Metadiscourse: What is it and where is it going? Journal of Pragmatics, 113, 16-29.

Hyland, K., \& Jiang, F. K. (2016). Change of attitude? A diachronic study of stance. Written Communication, 33(3), 251274.

Hyland, K., \& Jiang, F. K. (2018). "In this paper we suggest": Changing patterns of disciplinary metadiscourse. English for Specific Purposes, 51, 18-30.

Hyland, K., \& Tse, P. (2005). Hooking the reader: A corpus study of evaluative that in abstracts. English for Specific Purposes, 24(2), 123-139.

Jiang, F. K., \& Hyland, K. (2017). Metadiscursive nouns: Interaction and cohesion in abstract moves. English for Specific Purposes, 46, 114.
Johns, A. M. (1997). Text, role, and context: Developing academic literacies. New York: Cambridge University Press.

Johns, A. M. (2011). The future of genre in L2 writing: Fundamental, but contested, instructional decisions. Journal of Second Language Writing, 20(1), 56-68.

Lillis, T. (2008) Ethnography as method, methodology, and "deep theorizing". Written Communication, 25, 353-388.

Martin, J. R., \& White, P. R. R. (2005). The language of evaluation: Appraisal in English. London: Palgrave Macmillan.

Miller, C. R. (1984). Genre as social action. Quarterly Journal of Speech, 70, 151-167.

Paltridge, B. (1995). Working with genre: A pragmatic perspective. Journal of Pragmatics, 24(4), 393-406.

Paltridge, B. (2013). Genre and English for specific purposes. In B. Paltridge \& S. Starfield (Eds.), Handbook of English for specific purposes (pp. 347-366). Malden, MA: Wiley-Blackwell.

Qin, W., \& Uccelli, P. (2019). Metadiscourse: Variation across communicative contexts. Journal of Pragmatics, 139, 22-39.

Stotesbury, H. (2003). Evaluation in research article abstracts in the narrative and hard sciences. Journal of English for Academic Purposes, 2(4), 327-342.

Swales, J. (1990). Genre analysis. Cambridge: Cambridge University Press.

Swales, J. (1998). Other floors, other voices: A textography of a small university building. Mahwah, NJ: Erlbaum.

Swales, J. (2004). Research Genres: Exploration and Applications. Cambridge: Cambridge University Press.

Tardy, C., \& Swales, J. M. (2014). Genre analysis. In K. P. Schneider, \& A. Barron (Eds.), Pragmatics of Discourse (pp. 165-187). Berlin: De Gruyter Mouton. 